\title{
Ultrasonic condition boosts up the rate of phase transfer catalyzed polymerization of acrylonitrile in two-phase system
}

\author{
Elumalai Marimuthu' ${ }^{1}$ Vajjiravel Murugesan ${ }^{1}$
}

Received: 8 June 2017 / Accepted: 23 August 2017/Published online: 5 September 2017

(C) The Author(s) 2017. This article is an open access publication

\begin{abstract}
An ultrasound condition associated with phasetransfer catalyst (PTC) has great diverse applications in synthesis of various organic and polymeric materials because of its fast reaction and high yield in short period of time. Phase transfer catalyst (cetyltrimethylammonium bromide as PTC) extracts the reactive radical anion from aqueous phase and transfer to organic phase whilst ultrasound condition enhances the radical formation; consequently, acrylonitrile was polymerized in ethyl acetate/ water two-phase system at $60 \pm 1{ }^{\circ} \mathrm{C}$ under ultrasound $(25 \mathrm{kHz} / 300 \mathrm{~W})$ and silent condition. The rate of polymerization $\left(R_{\mathrm{p}}\right)$ was doubled under ultrasound compare to silent condition. The various experimental parameters such as monomer, initiator, catalyst and temperature, solvent polarity on the rate of polymerization was studied in both conditions. The activation energy $\left(E_{\mathrm{a}}\right)$ and other thermodynamic parameters were calculated. The $E_{\mathrm{a}}$ value of ultrasound condition supports the enhancement of rate of polymerization. On the basis of observed results, a suitable kinetic model, mechanism and effect of ultrasound in the rate of polymerization were discussed. The obtained polymer was analyzed by TG/DTA and FT-IR. The viscosity average molecular weight of the polymer was found to be $6.8526 \times 10^{4} \mathrm{~g} \mathrm{~mol}^{-1}$.
\end{abstract}

Keywords Kinetics · Ultrasound condition · Phase-transfer catalyst $\cdot$ Rate of polymerization - Two-phase system

Vajjiravel Murugesan

chemvel@rediffmail.com; vajjiravel_m@bsauniv.ac.in

1 Department of Chemistry, B S Abdur Rahman Crescent University, Vandalur, Chennai 600 048, India

\section{Introduction}

Acrylonitrile (AN) is commercially attractive and important functional monomer for the synthesis of acrylonitrilebased copolymers that are used as plastics, rubbers and synthetic fibers and for making various composites for versatile applications. It is also an important common precursor for making carbon and graphite fibers. PAN and its copolymers are usually prepared by free radical polymerization methods. Free radical polymerization is a scientifically, technologically and commercially important polymerization method [1-3]. Polymerization in waterbased systems has been studied extensively because it combines the environmental and technical advantages of polymerization in an aqueous medium with an ability to synthesize a wide range of molecular weights of polymers. There is an increasing intention to minimize the use of organic solvents in polymerization and other organic reactions.

Water as a green solvent has several attractive characteristics such as non-toxicity, cheap cost and ready availability for versatile applications. A wide range of radical initiation techniques, including thermal $[4,5]$, redox [6-8], photochemical [9], electrochemical [10] and radiolysis [11] methods have been successfully employed for aqueous polymerizations. Among them thermal (water-soluble initiator) induced polymerization, utilizes the moderate or high thermal energy to initiate chain reactions to form polymers. Water-soluble initiator has profound advantages over other initiators like organic soluble initiator. However, the insolubility of such initiators in organic solvents and monomers makes their use impractical for the polymerization. Fortunately, thanks to phase transfer catalyst (PTC) reaction methodology [12-17], phase transfer catalyst facilitates the migration of a reactant from one phase to 
another in which the reaction occurs, which avoids mass transfer limitations and increases the efficiency of twophase system. This type of catalyst is very versatile for synthesis of polymers and organic compounds in both academia and industry because of its simple experimental process, mild reaction conditions, being inexpensive and the possibility to be implemented on a large scale [18-21]. It has been reported such water-soluble initiators can be used effectively in the polymerization of vinyl monomers with the help of various phase transfer catalysts [22-44].

Applications of ultrasound in different arena are well documented in books $[45,46]$ and reviews [47-50]. The use of PTC and ultrasound techniques in the area of polymerization has been gaining remarkable consideration in industrial and academic arena because it is a potent and versatile technology which offers several advantages. It has been reported that a combination of PTC and ultrasound condition is a valuable technique to enhance the reaction rate in an organic heterogeneous reactions [51-56] and also successfully employed in different polymerization techniques to synthesis polymers [57], homopolymers, block copolymers [58], hydrogels [59] and polymer-inorganic composites, etc. [49]. To the best of our knowledge the combined approach of PTC and ultrasound in free radical polymerization of vinyl monomers was limited [60-65]. By considering above all, we utilize this unique combined approach in polymerization of acrylonitrile (AN) using commercially available cetyltrimethylammonium bromide (CTMAB) as PTC and potassium peroxydisulfate (PDS) as water-soluble initiator in ethyl acetate/water two-phase system at $60 \pm 1{ }^{\circ} \mathrm{C}$ under inert atmosphere with silent and an ultrasound condition $(25 \mathrm{kHz} ; 300 \mathrm{~W})$. The systematic investigation showed that the rate of polymerization $\left(R_{\mathrm{p}}\right)$ was doubled under ultrasound compared to silent polymerization. The effects of various reaction variables on the rate of polymerization were investigated, including variation of monomer, initiator, catalyst and temperature, organic solvent polarity in ultrasound and silent condition. An extraction reaction model was proposed to explain the characteristics of the polymerization and its significance was discussed.

\section{Experimental}

\section{Chemicals and solvents}

Acrylonitrile (AN) was purchased from Sigma Aldrich and used after the removal of inhibitors. The inhibitor was removed by washing the monomer with $5 \%$ aqueous $\mathrm{NaOH}$ and water, followed by drying over $\mathrm{CaCl}_{2}$ and then distilled at $78{ }^{\circ} \mathrm{C}$ at atmospheric pressure. The initiator, potassium peroxydisulfate (PDS) (Merck, India) was purified twice by recrystallization in cold water. Cetyltrimethylammonium bromide (CTMAB) (Sigma Aldrich, India) was used without purification. The solvents [benzene, cyclohexanone, cyclohexane, ethyl acetate, toluene, anhydrous $\mathrm{N}, \mathrm{N}$ dimethylformamide (DMF) and methanol] were used as polymerization medium, and for purification of polymers by precipitation, washing and viscosity measurements were supplied by Merck, Avra and SRL India were used as received. The double-distilled water was used to make an aqueous phase.

\section{Instruments}

The ultrasound generator having a thermostatic bath equipped with dual frequency ( 25 and $45 \mathrm{kHz}$ and power of $300 \mathrm{~W}$; Elma Ultrasonicator with dual frequency, Germany) was used for the polymerization (Fig. 1a) The FTIR spectrum of poly (acrylonitrile) was recorded on a FTIR spectrometer (JASCO) in the spectral region from 4000 to $500 \mathrm{~cm}^{-1}$. The thermal analyses of poly (acrylonitrile) were carried out by using TA instruments. The sample weight $4.4340 \mathrm{mg}$ was loaded in alumina pans and ramped

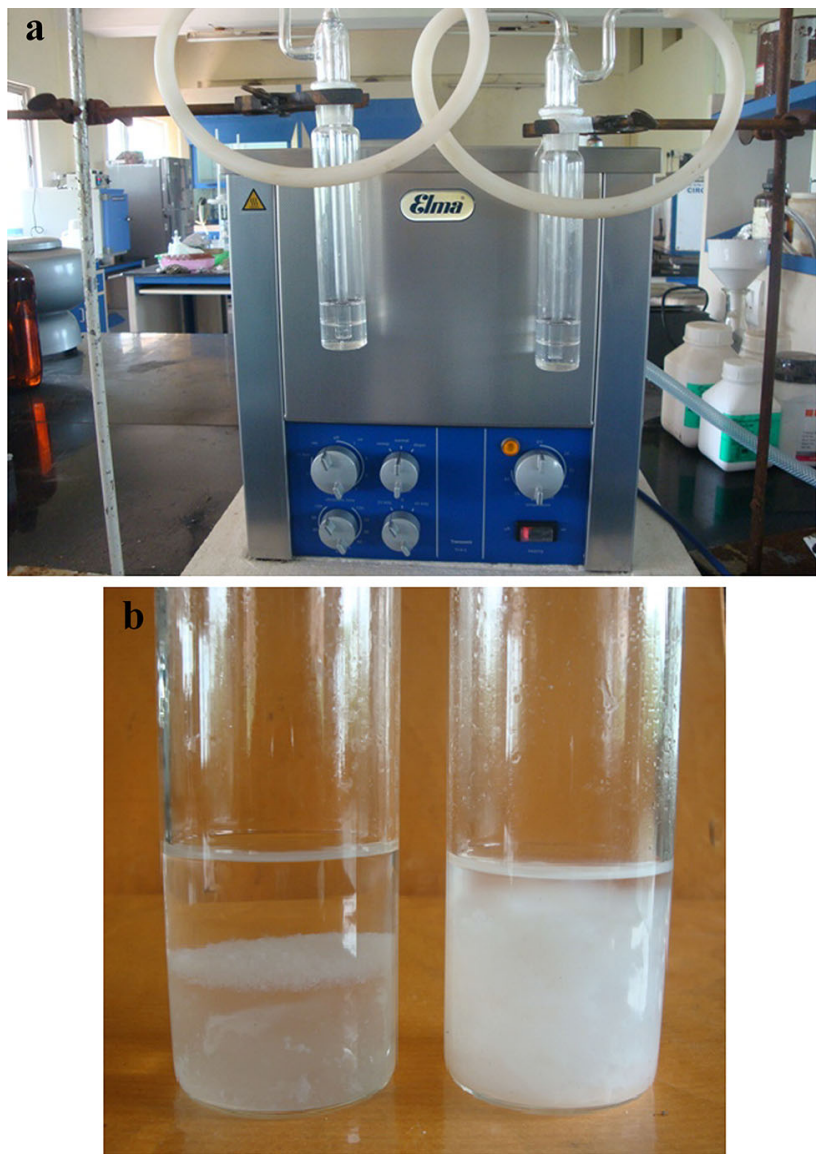

Fig. 1 a An ultrasonicator used for the polymerization. b Differences in the rate of precipitation of poly(acrylonitrile) under ultrasound(right) and silent (left) condition 
at heating rate $15{ }^{\circ} \mathrm{C}$ per minute from ambient to $800{ }^{\circ} \mathrm{C}$ in nitrogen atmosphere. The viscosity measurements were carried out in $N, N$-dimethylformamide at $30 \pm 1{ }^{\circ} \mathrm{C}$ using an Ubbelohde viscometer and viscosity average molecular weight of the polymer was calculated using Mark-Houwink equation [66].

\section{Polymerization procedure}

An aqueous phase contains the calculated amount of phase transfer catalyst (CTMAB), potassium sulphate (for maintaining the ionic strength) and sulphuric acid (for maintaining the uniform acid strength) and organic phase contains monomer in solvent was taken in polymerization vessel (aqueous and organic phase total volume: $20 \mathrm{~mL}$ and ratio is 1:1). Then, the polymerization tube was deoxygenated using nitrogen gas for $15 \mathrm{~min}$. The ultrasound equipment was set in a constant temperature $\left(60 \pm 1{ }^{\circ} \mathrm{C}\right)$ with ultrasound condition of $25 \mathrm{kHz} ; 300 \mathrm{~W}$. Polymerization was started by adding the calculated amount of de-aerated initiator (PDS) to the reaction vessel and the ultrasound was activated. During the reaction, the poly (acrylonitrile) was precipitated at the bottom of vessel. After stipulated time of period, the reaction was arrested by pouring the reaction mixture into an ice-cold methanol. The polymers were filtered quantitatively through a G-4 sintered glass crucible, washed several times with anhydrous methanol followed by distilled water and finally dried at $50{ }^{\circ} \mathrm{C}$ in a vacuum oven to get a constant weight. The kinetic studies of polymerization were carried out with varying the content of monomer, initiator, catalyst and temperature by adopting the above procedure (Scheme 1).

The rate of polymerization $\left(R_{\mathrm{p}}\right)$ was calculated from the weight of the polymer obtained using the following formula: $R_{\mathrm{p}}=1000 \times W / V \times t \times M ; W$-obtained weight of the polymer in $\mathrm{g} ; \mathrm{V}$-volume of the reaction mixture in $\mathrm{mL} ; t$-reaction time in seconds; $M$-molecular weight of the monomer $\left(\mathrm{g} \mathrm{mol}^{-1}\right)$.

\section{Kinetic model}

Most of the phase-transfer catalyzed reactions involve an aqueous liquid phase and an organic liquid phase (liquid- liquid PTC) or a solid phase and an organic liquid phase (solid-liquid PTC). In liquid-liquid PTC, some of the most commonly used catalysts are quaternary ammonium and phosphonium salts. Generally, they are easily separated from reaction products, reasonably inexpensive and they may undergo easy decomposition at moderate temperature. In two-phase system, the role of phase transfer catalyst $\left(\mathrm{Q}^{+} \mathrm{X}^{-}\right)$is act as a vehicle to transfer of anion $\left(\mathrm{Y}^{-}\right)$from aqueous phase (initiator: $\mathrm{K}^{+} \mathrm{Y}^{-}$) to organic phase, at the interface between the phases it was decompose $\left(\mathrm{Q}^{+} \mathrm{Y}^{-}\right)$ and produce the radical ions which initiates (M: monomer) the polymerization at $60 \pm 1{ }^{\circ} \mathrm{C}$ and with ultrasound condition. Further, in situ regenerated $\mathrm{Q}^{+} \mathrm{X}^{-}$in aqueous phase which could continue the phase transfer cyclic polymerization process has shown in Scheme 2. The chemical effects of ultrasound attributed to intense local conditions were generated due to cavitations (usually in single electron transfer reactions) involving the formation of free radicals. However, PTC reactions proceed through the ionic transfer and rate increase due to mass transfer. In two-phase system, cavitational collapse may occur near in liquid-liquid interface, disrupt the interface and push of one liquid to the other like forming fine emulsion and leading to a dramatic enhancement in interfacial contact area across which transfer of species can take place [47-49]. Generally, the phase transfer catalyst initiates the reaction by the transfer of species from one phase to another and ultrasound facilitates this transfer by increasing the interfacial area across which this transfer occurs; thus the rate of polymerization was enhanced under ultrasound compare to silent condition. The difference in the rate of precipitation of poly (acrylonitrile) under ultrasound and silent condition was shown in the Fig. $1 \mathrm{~b}$.

\section{Results and discussion}

The kinetics of ultrasound-assisted phase transfer catalyzed radical polymerization of acrylonitrile was studied in ethyl acetate/water two-phase system with silent (without ultrasonic) and ultrasonic condition $(25 \mathrm{kHz}, 300 \mathrm{~W})$. The variation of monomer, initiator, catalyst and temperature, solvent polarity on the rate of polymerization was explored in both conditions.

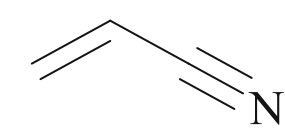

Acrylonitrile

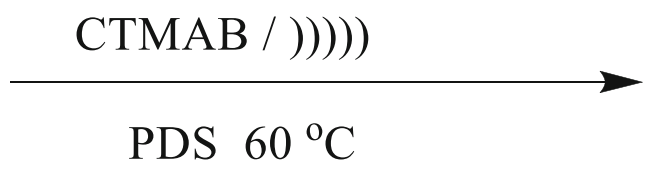

PDS $60{ }^{\circ} \mathrm{C}$

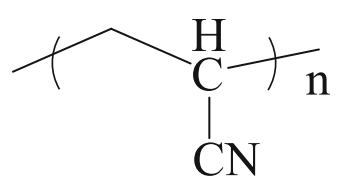

Poly(acrylonitrile) (PAN)

Scheme 1 Ultrasound assisted phase transfer catalyzed polymerization of acrylonitrile

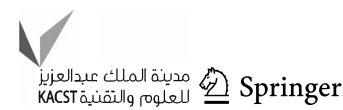


Scheme 2 Kinetic model of an ultrasound and PTC assisted polymerization of acrylonitrile in two phase system

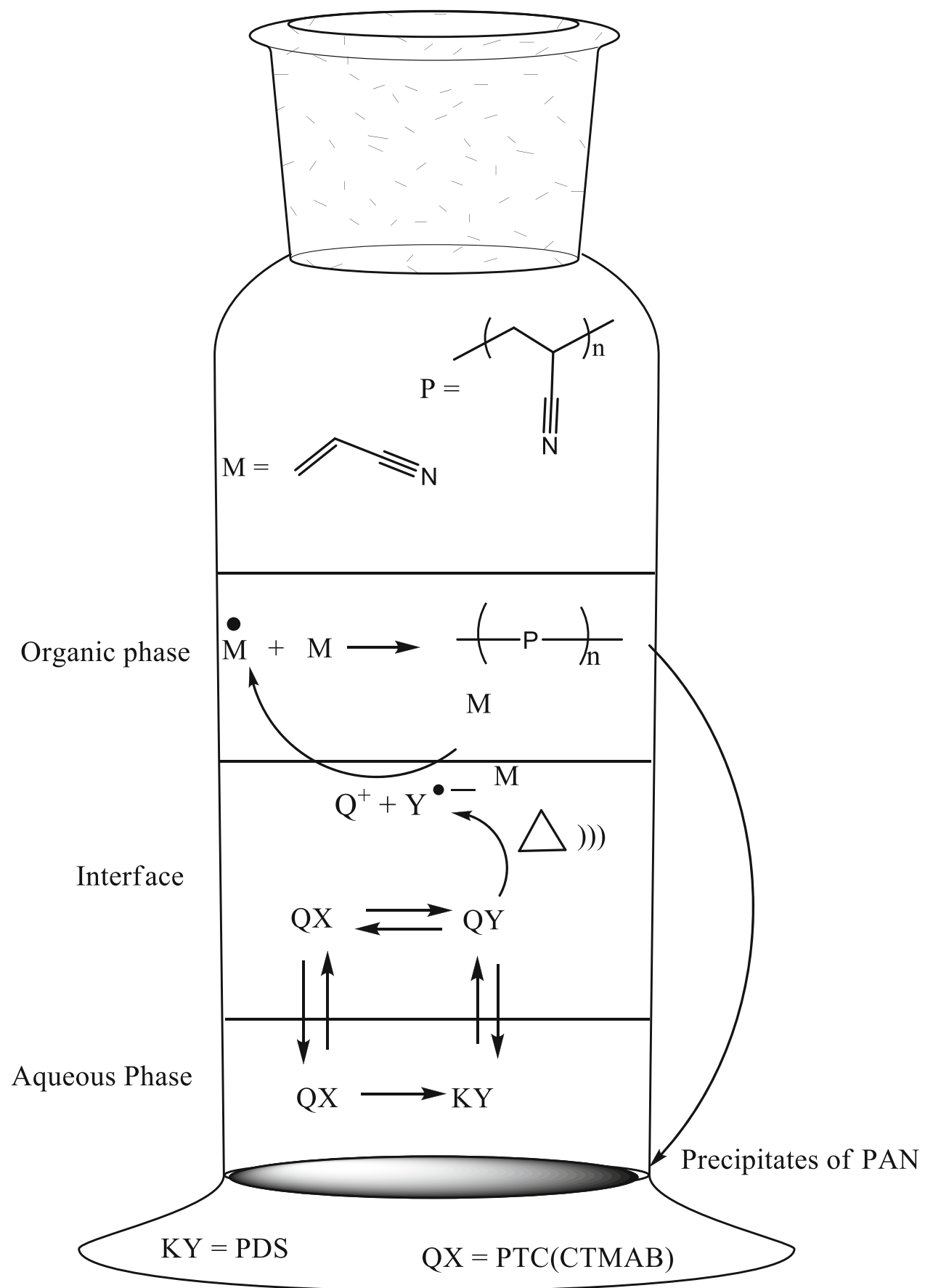

\section{Variation of ultrasound condition on the $\boldsymbol{R}_{\mathrm{p}}$}

Variation of ultrasound condition on the rate of polymerization of AN-CTMAB-PDS system was examined with 0 , 25 and $45 \mathrm{kHz}$ giving the output power of $300 \mathrm{~W}$ and the results are presented in Table $1 . R_{\mathrm{p}}$ was doubled and tripled for 25 and $45 \mathrm{kHz}$ compared to silent condition (without ultrasound). The rate of phase transfer catalyzed polymerization of acrylonitrile was significantly enhanced under ultrasound condition. Ultrasound $(20-100 \mathrm{kHz})$ has been found to enhance the rate of reactions in liquid-liquid and solid-liquid heterogeneous systems. Ultrasound creates physical and chemical effects in the polymerization reaction. In physical effects, acoustic cavitation gives an intense mixing and strong dispersion of mixture take place. While, in chemical effects, the acoustic cavitation facilitates the formation of radicals, this will enhance the polymerization process. Simply, an ultrasound pulse facilitates the mixing of two phases (liquid-liquid heterogeneous system) and increases the contact between the 
Table 1 Variation of ultrasound condition on the $R_{\mathrm{p}}$

\begin{tabular}{lll}
\hline $0 \mathrm{kHz}, R_{\mathrm{p}} \times 10^{5} \mathrm{~mol} \mathrm{dm}^{-3} \mathrm{~s}^{-1}$ & $25 \mathrm{kHz}, R_{\mathrm{p}} \times 10^{5} \mathrm{~mol} \mathrm{dm}^{-3} \mathrm{~s}^{-1}$ & $45 \mathrm{kHz}, R_{\mathrm{p}} \times 10^{5} \mathrm{~mol} \mathrm{dm}{ }^{-3} \mathrm{~s}^{-1}$ \\
\hline 0.93 & 2.54 & 3.72 \\
\hline
\end{tabular}

Reaction condition: [AN]: $2.0 \mathrm{~mol} \mathrm{dm}{ }^{-3} \mathrm{~s}^{-1}$; [PDS]: $2.0 \times 10^{-2} \mathrm{~mol} \mathrm{dm}^{-3} \mathrm{~s}^{-1}$; [CTMAB]: $2.0 \times 10^{-2} \mathrm{~mol} \mathrm{dm}^{-3} \mathrm{~s}^{-1} ;\left[\mathrm{H}^{+}\right.$]: $0.50 \mathrm{~mol} \mathrm{dm}^{-3} \mathrm{~s}^{-1}$; $[\mu]$ : $0.20 \mathrm{~mol} \mathrm{dm}^{-3} \mathrm{~s}^{-1}$; Time: $60 \mathrm{~min}$; temperature: $60 \pm 1{ }^{\circ} \mathrm{C}$

interface regime and transfer of energy directly to the dissolved chemical reactants. Short-lived temperature and pressure cavitations may contribute to rapid decomposition of initiator, thereby increase the formation radical leads to fast polymerization process [48, 49, 51]. The enhancement in the rate of phase-transfer catalyzed polymerization under ultrasound condition is attributed to the aforementioned reason. The combined approach of PTC and ultrasound is one of best techniques to enhance the reaction rate [60-65]. On the other hand, ultrasound by itself has been suggested as an alternative to PTC in few kinds of reactions. All the experimental variations were performed at $25 \mathrm{kHz}$ with output power of $300 \mathrm{~W}$ for ultrasound condition.

\section{Variation of time on the $R_{\mathrm{p}}$}

The rate of polymerization was examined at different time intervals by keeping the variations of monomer, initiator, catalyst and temperature constant under ultrasound and silent conditions. The plot of $R_{\mathrm{p}}$ versus time showed an increase to some extent, decreased thereafter and then remained constant. Initially, $R_{\mathrm{p}}$ increases due to less viscous of the medium and thereafter $R_{\mathrm{p}}$ reaching constant value [35-37]. The steady-state rate of polymerization of acrylonitrile was arrived at $60 \mathrm{~min}$ for both conditions. Further, it was observed that $R_{\mathrm{p}}$ was doubled in the presence of ultrasonic condition (Fig. 2). The reason was mainly attributed to the mechanical and chemical effect of ultrasound which can enhance the mixing of two phase effectively making like homogenous phase and helps the formation and transfer of more radical along with phase transfer catalytic polymerization process [60-65]. The polymerization of acrylonitrile with different PTC was reported $[25,34,35,42]$ in the absence of ultrasound condition.

\section{Variation of $[\mathrm{AN}]$ on the $\boldsymbol{R}_{\mathrm{p}}$}

The variation of $[\mathrm{AN}]$ on the rate of polymerization $\left(R_{\mathrm{p}}\right)$ was studied by varying the concentrations from 4.5 to $9.5 \mathrm{~mol} \mathrm{dm}^{-3}$ and keeping other variables constant under ultrasound and silent conditions. A plot of $6+\log R_{\mathrm{p}}$ versus $3+\log [\mathrm{AN}]$ was found at the slope of 1.45 and 1.54. From the plots the variation of monomer concentration was fallen in the region order of unity for ultrasonic

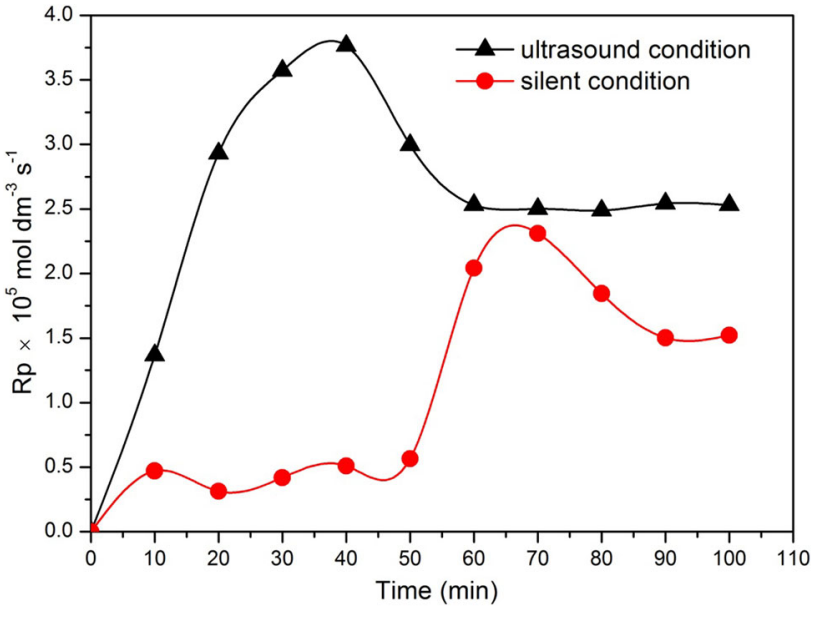

Fig. 2 Variation of time on the $R_{\mathrm{p}}$. Reaction condition: [AN]: $2.0 \mathrm{~mol} \mathrm{dm}^{-3}$; [PDS]: $2.0 \times 10^{-2} \mathrm{~mol} \mathrm{dm}{ }^{-3}$; [CTMAB]: $2.0 \times 10^{-2}$ mol dm ${ }^{-3} ;\left[\mathrm{H}^{+}\right]: 0.50 \mathrm{~mol} \mathrm{dm}{ }^{-3} ;[\mu]: 0.20 \mathrm{~mol} \mathrm{dm}^{-3}$; temperature: $60 \pm 1{ }^{\circ} \mathrm{C}$; ultrasound condition: $25 \mathrm{kHz} / 300 \mathrm{~W}$

and silent condition. $R_{\mathrm{p}}$ increases with an increase of monomer concentration. The order of unity with respect to monomer was confirmed from the straight line passing through origin in the plot of $R_{\mathrm{p}}$ versus [AN] (Fig. 3a, b). The order of unity with respect to monomer concentration was well documented in the polymerization of different vinyl monomers using PTC [37-40]. A higher reaction order with respect to acrylonitrile monomer was reported in the absence of ultrasonic condition [35, 42].

\section{Variation of [PDS] on the $R_{\mathrm{p}}$}

The variation of [PDS] on the rate of polymerization was studied by varying the range of $1.5-2.5 \mathrm{~mol} \mathrm{dm}^{-3}$ at fixed concentrations of other parameters in association with stated ultrasound and silent condition. The $R_{\mathrm{p}}$ increases with an increasing concentration of initiator for AN-PTCPDS system. The initiator order value was obtained from the slope of plot of $6+\log R_{\mathrm{p}}$ versus $3+\log$ [PDS] was found to be 1.25 and 1.32. The plot of $R_{\mathrm{p}}$ versus [PDS] is linear passing through the origin supporting the above deduction (Fig. 4a, b). The higher initiator order can be explained by gel effect or diffusion controlled termination constant [23]. In addition, higher order of initiator concentration suggests that the termination is bimolecular and monomer-induced decomposition of PDS was absent [23]. 

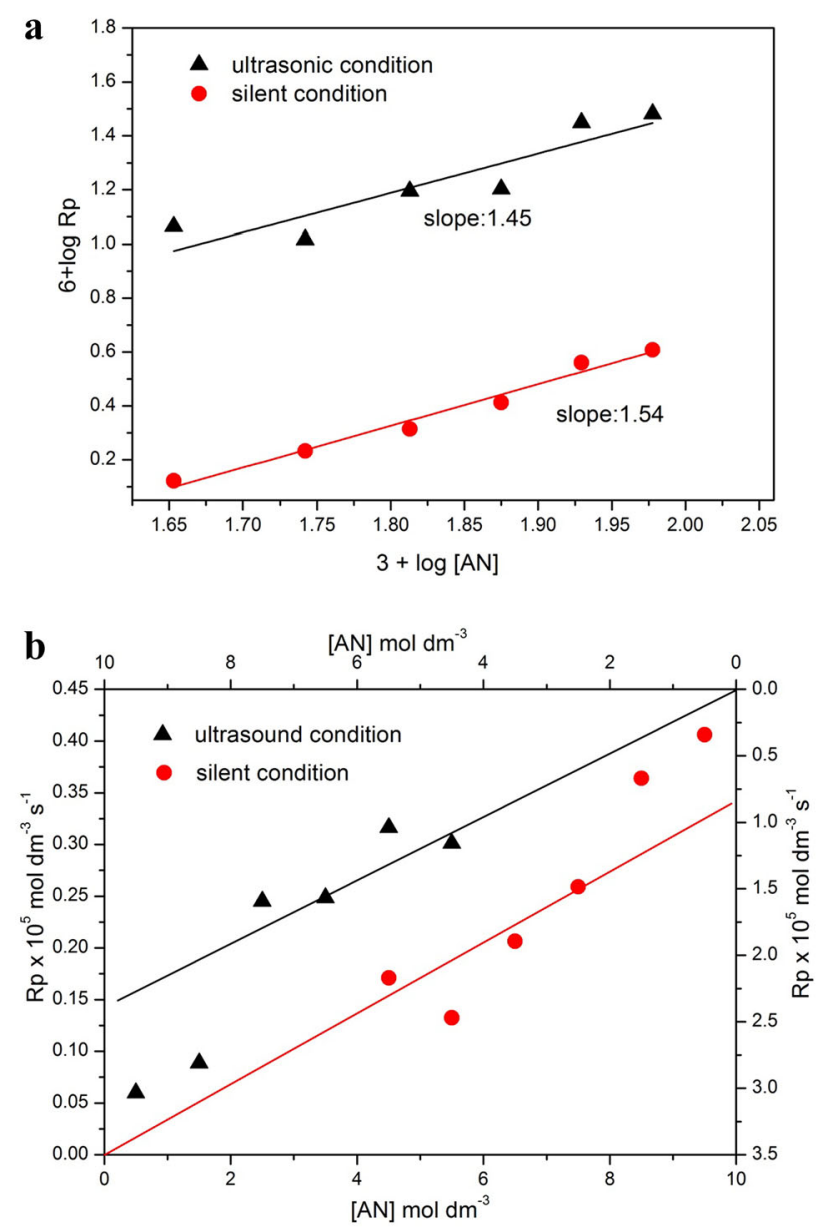

Fig. 3 Variation of [AN] on the $R_{\mathrm{p}}$. a Plot of $6+\log R_{\mathrm{p}}$ versus $3+\log [\mathrm{AN}]$. b Plot of $R_{\mathrm{p}}$ versus [AN]. Reaction condition: [PDS]: $2.0 \times 10^{-2} \mathrm{~mol} \mathrm{dm}{ }^{-3} ; \quad[\mathrm{CTMAB}]: 2.0 \times 10^{-2} \mathrm{~mol} \mathrm{dm}^{-3} ;\left[\mathrm{H}^{+}\right]$: $0.50 \mathrm{~mol} \mathrm{dm}^{-3}[\mu]$ : $0.20 \mathrm{~mol} \mathrm{dm}^{-3}$; temperature: $60 \pm 1{ }^{\circ} \mathrm{C}$; time: $60 \mathrm{~min}$; ultrasound condition: $25 \mathrm{kHz} / 300 \mathrm{~W}$

The greater than half order with respect to initiator concentration was reported in phase-catalyzed polymerization systems [36-39]. The results showed that the $R_{\mathrm{p}}$ value was doubled in the presence of ultrasound than silent condition. It implies that the reaction between PDS (KY) and PTC (QX) was rapid and facilitated the more easy formation of $\mathrm{QS}_{2} \mathrm{O}_{8}(\mathrm{QY})$ in the presence of ultrasonic condition. The formed $\mathrm{QS}_{2} \mathrm{O}_{8}(\mathrm{KY})$ has more lipophilic character and, therefore, it easily entered into the organic phase from aqueous phase, thereby quickening the polymerization process. Thus, observed rate was high in the presence of ultrasound condition.

\section{Variation of [PTC] on the $\boldsymbol{R}_{\mathrm{p}}$}

The variation in the amount of phase transfer catalyst, cetyltrimethylammonium bromide (CTAMB) on the rate of polymerization was examined from 1.5 to $2.5 \mathrm{~mol} \mathrm{dm}^{-3}$ at
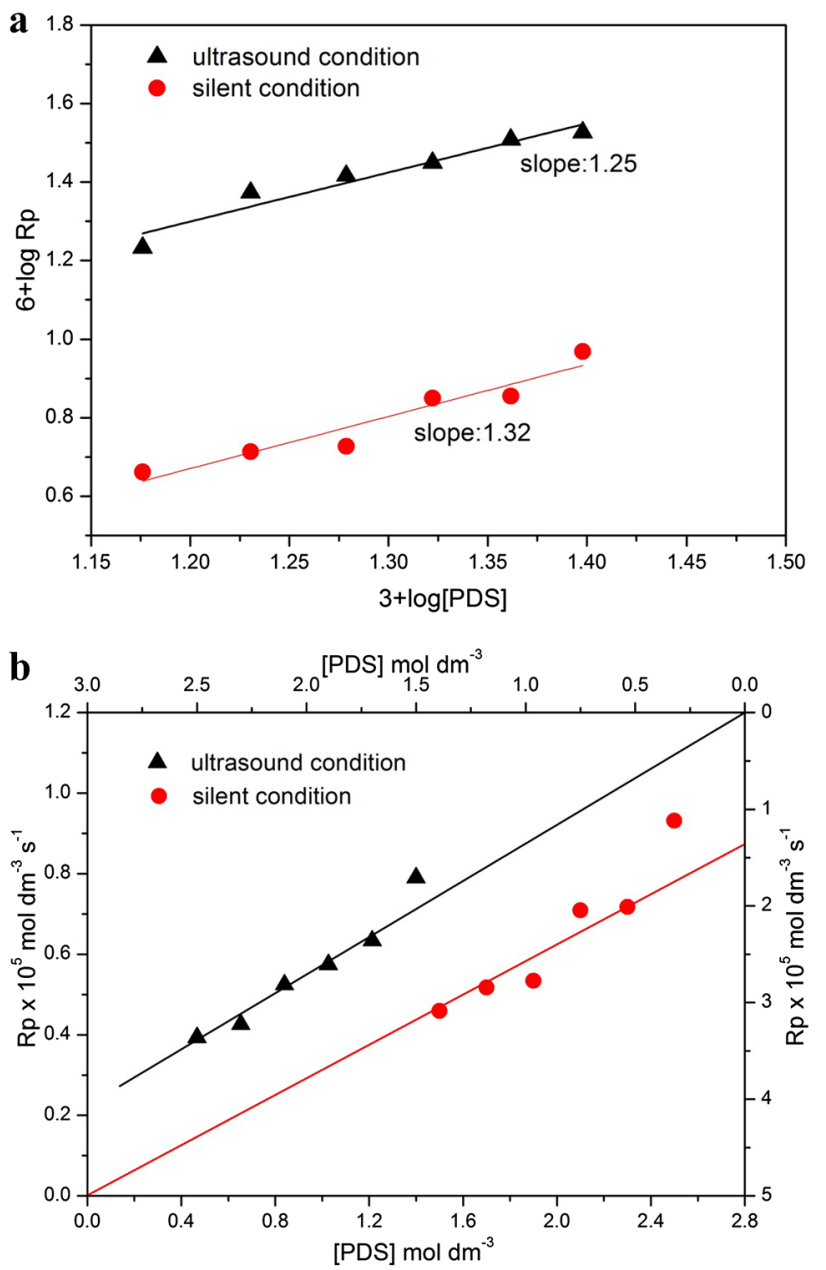

Fig. 4 Variation of [PDS] on the $R_{\mathrm{p}}$. a Plot of $6+\log R_{\mathrm{p}}$ versus $3+\log$ [PDS]. b Plot of $R_{\mathrm{p}}$ versus [PDS]. Reaction condition: [AN]: $2.0 \mathrm{~mol} \mathrm{dm}^{-3} ; \quad$ [CTMAB]: $2.0 \times 10^{-2} \mathrm{~mol} \mathrm{dm}^{-3} ; \quad\left[\mathrm{H}^{+}\right]$: $0.50 \mathrm{~mol} \mathrm{dm}^{-3}$; $[\mu]: 0.20 \mathrm{~mol} \mathrm{dm}^{-3}$; temperature: $60 \pm 1{ }^{\circ} \mathrm{C}$; time: $60 \mathrm{~min}$; ultrasound condition: $25 \mathrm{kHz} / 300 \mathrm{~W}$

fixed conditions of other parameters under ultrasound and silent conditions. The slope of linear plot was obtained by plotting of $6+\operatorname{logs} R_{\mathrm{p}}$ versus $3+\log$ [CTMAB]; the order with respect to [CTMAB] was found to be 0.70 and 1.32 for ultrasound and silent conditions. The observed order was confirmed from the straight line passing through the origin in a plot of $R_{\mathrm{p}}$ versus [CTMAB] (Fig. 5a, b). $R_{\mathrm{p}}$ increased with an increase in the concentration of initiator. It is due to collision between initiator and catalyst was enhanced in the presence of ultrasound condition. In such a way more reactive radicals enhance the polymerization process [60-65].

Blank experiment: polymerization of acrylonitrile was performed by adopting aforementioned polymerization procedure without adding catalyst at $60 \pm 1{ }^{\circ} \mathrm{C}$ for $60 \mathrm{~min}$ under silent and ultrasonic conditions. The changes in the appearance of two-phase system were noticed (turbid 

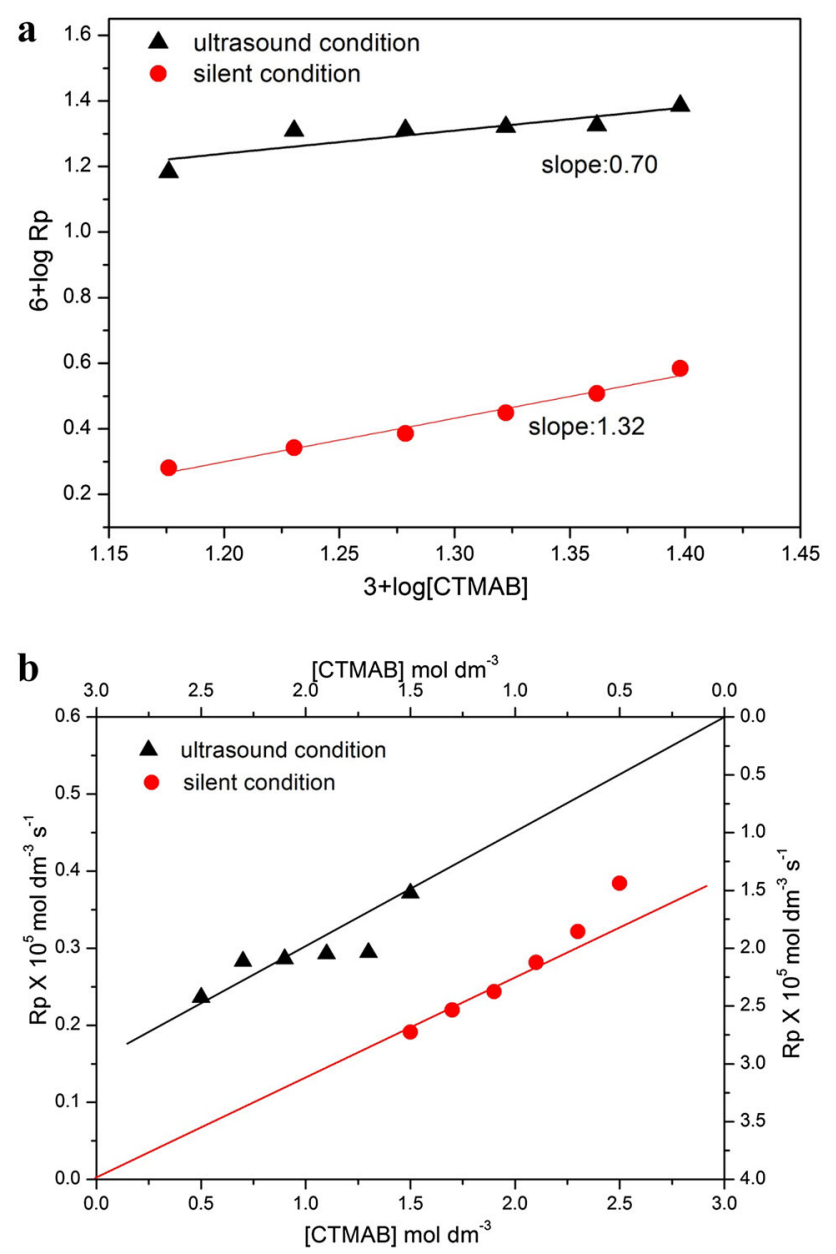

Fig. 5 Variation of [CTMAB] on the $R_{\mathrm{p}}$. a Plot of $6+\log R_{\mathrm{p}}$ versus $3+\log [\mathrm{CTMAB}]$. b Plot of $R_{\mathrm{p}}$ versus [CTMAB]. Reaction condition: [AN]: $2.0 \mathrm{~mol} \mathrm{dm}{ }^{-3}$; [PDS]: $2.0 \times 10^{-2} \mathrm{~mol} \mathrm{dm}^{-3} ;\left[\mathrm{H}^{+}\right]$: $0.50 \mathrm{~mol} \mathrm{dm}^{-3 ;}[\mu]: 0.20 \mathrm{~mol} \mathrm{dm}^{-3}$; temperature: $60 \pm 1{ }^{\circ} \mathrm{C}$; time: $60 \mathrm{~min}$; ultrasound condition: $25 \mathrm{kHz} / 300 \mathrm{~W}$

appearance), but while pouring the reaction mixture into methanol it disappeared. This observation was the proof for role of catalyst on polymerization reaction. The polymerization did not occur in the absence of catalyst as well the presence of ultrasound condition even after few minutes.

\section{Variation of temperature on the $\boldsymbol{R}_{\mathrm{p}}$}

Temperature is an important factor affecting the reaction rate and side reaction would be possible at high temperature. The variation of temperature from 50 to $65^{\circ} \mathrm{C}$ on the rate of polymerization was studied by keeping other parameters constant under ultrasound condition. As predicted, the $R_{\mathrm{p}}$ increased with an increase in the temperature. The reason is that the energy of reactant molecule is higher and the collision between the molecules is also increased while rising temperature. The activation energy $\left(E_{\mathrm{a}}\right)$ was obtained from the Arrhenius plot of $6+\log R_{\mathrm{p}}$

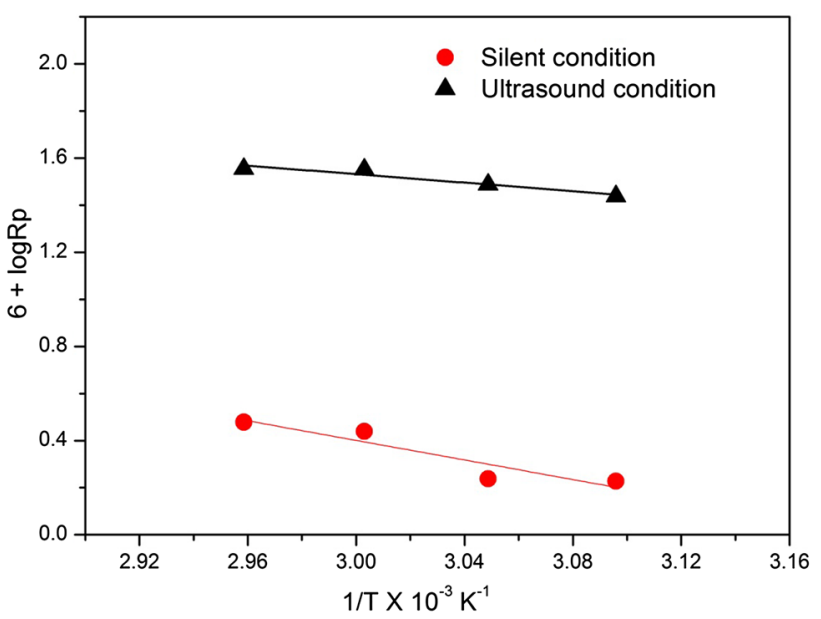

Fig. 6 Variation of temperature on the $R_{\mathrm{p}}$. Reaction condition: [AN]: $2.0 \mathrm{~mol} \mathrm{dm}^{-3}$ [PDS]: $2.0 \times 10^{-2} \mathrm{~mol} \mathrm{dm}^{-3}$; [CTMAB]: $2.0 \times 10^{-2}$ mol dm${ }^{-3}$; $\left[\mathrm{H}^{+}\right]: 0.50 \mathrm{~mol} \mathrm{dm}^{-3}$; $[\mu]: 0.20 \mathrm{~mol} \mathrm{dm}^{-3}$; time: $60 \mathrm{~min}$; ultrasound condition: $25 \mathrm{kHz} / 300 \mathrm{~W}$

versus $1 / T$ (Fig. 6 ). The activation energy $\left(E_{\mathrm{a}}\right)$ of 17.32 and $39.63 \mathrm{~kJ} \mathrm{~mol}^{-1}$ was obtained for ultrasound and silent condition. It was obvious that the low $E_{\mathrm{a}}$ value reveals that the reaction rate is fast, whereas high $E_{\text {a }}$ value suggests slow reaction rate. From that we can conclude that there was much influence on the rate of polymerization under ultrasound condition. The other attributing factor was that the number of cavitation bubbles (i.e. reaction loci) increases with increase in temperature and also increases in collision of reactants at high temperature [60-62, 64, 65]. The other thermodynamic parameters such as entropy of activation $\left(\Delta S^{\#}\right)$, enthalpy of activation $\left(\Delta H^{\#}\right)$ and free energy of activation $\left(\Delta G^{\#}\right)$ have been calculated and presented in Table 2.

\section{Variation of $\mathrm{pH}$ on the $\boldsymbol{R}_{\mathrm{p}}$}

The variation of acid concentrations $(\mathrm{pH})$ in the range of $0.16-0.24 \mathrm{~mol} \mathrm{dm}^{-3}$ on the rate of polymerization was investigated at fixed concentrations of monomer, initiator and catalyst. The rate of polymerization was slightly increases and then reaches the constant values in the employed acid concentrations. A similar kind of observation was reported in the phase-transfer catalyzed polymerization of different vinyl monomers [33-41].

\section{Variation of organic solvents polarity on the $\boldsymbol{R}_{\mathrm{p}}$}

The selection of organic solvent plays vital role in phasetransfer catalyzed reaction. Generally, the dielectric constants are used as the main index in choosing an appropriate organic solvent. The effect of the organic solvents on the reactivity involves the solubility of the catalyst, 
Table 2 Thermodynamic parameters

\begin{tabular}{lllll}
\hline Condition & $E_{\mathrm{a}} \mathrm{kJ} \mathrm{mol}^{-1}$ & $\Delta G^{\#} \mathrm{~kJ} \mathrm{~mol}^{-1}$ & $\Delta H^{\#} \mathrm{~kJ} \mathrm{mo}^{-1}$ & \multicolumn{1}{c}{$\Delta S^{\#} \mathrm{EU}$} \\
\hline Ultrasound & 17.32 & 50.98 & 14.57 & -109.34 \\
Silent & 39.63 & 58.12 & 36.95 & -63.57 \\
\hline
\end{tabular}

transition state of the reaction, ion transfer, salvation and interfacial phenomena which are difficult to predict for the new kind of reaction. Therefore, the variation of different organic solvents' polarity on $R_{\mathrm{p}}$ was explored under both the reaction conditions stated. The employed organic solvents, dielectric constants and obtained $R_{\mathrm{p}}$ value, were given in Table 3 and Fig. 7. Based on the observed experimental results, the order of the increasing the rate of polymerization for these solvents is cyclohexanone $>$ ethyl acetate $>$ toluene $>$ benzene $>$ cyclohexane. An increase in the rate of polymerization was attributed to an increase

Table 3 Variation of organic solvents polarity on the $R_{\mathrm{p}}$

\begin{tabular}{llll}
\hline Solvents & $\begin{array}{l}\text { Dielectric } \\
\text { constant }(\varepsilon)\end{array}$ & $\begin{array}{l}R_{\mathrm{p}} \times 10^{-5} \\
\mathrm{~mol} \mathrm{dm} \mathrm{dm}^{-1} \\
\text { (ultrasound) }\end{array}$ & $\begin{array}{l}R_{\mathrm{p}} \times 10^{-5} \\
\mathrm{~mol} \mathrm{dm} \\
\text { (silent) }\end{array}$ \\
\hline Cyclohexane & 2.02 & 4.0677 & 0.2010 \\
Benzene & 2.27 & 7.2441 & 0.4135 \\
Toluene & 2.38 & 7.8959 & 0.7512 \\
Ethyl acetate & 6.02 & 8.6353 & 1.2041 \\
Cyclohexanone & 18.20 & 9.5360 & 1.6438
\end{tabular}

Reaction condition: [AN]: $2.0 \mathrm{~mol} \mathrm{dm}^{-3 ;} \quad[\mathrm{PDS}]: 2.0 \times 10^{-2}$ mol dm ${ }^{-3}$; [CTMAB]: $2.0 \times 10^{-2} \mathrm{~mol} \mathrm{dm}^{-3} ;\left[\mathrm{H}^{+}\right]: 0.50 \mathrm{~mol} \mathrm{dm}{ }^{-3}$;

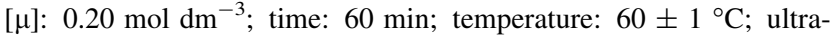
sound condition: $25 \mathrm{kHz} / 300 \mathrm{~W}$

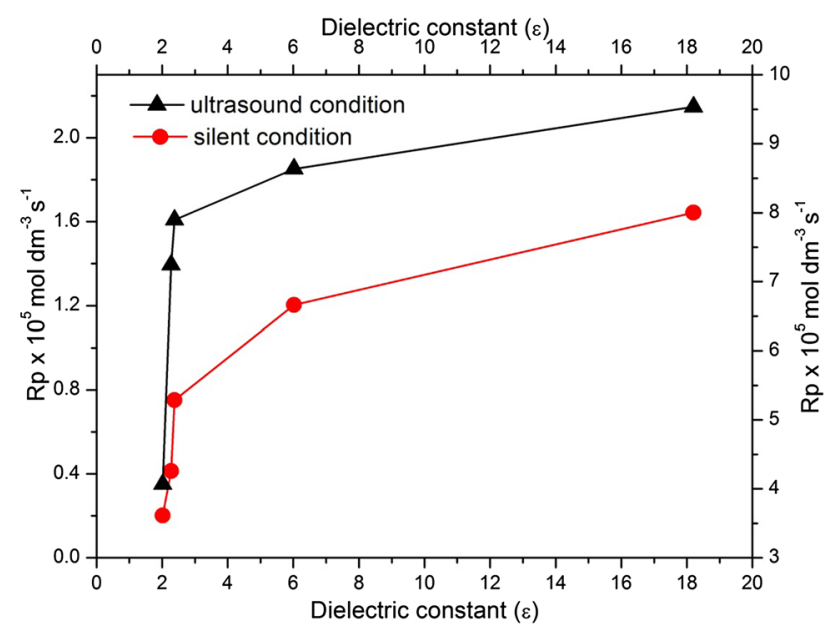

Fig. 7 Variation of organic solvents' polarity on $R_{\mathrm{p}}$. Plot of $R_{\mathrm{p}}$ versus dielectric constants of solvents. Reaction condition: [AN]: $2.0 \mathrm{~mol} \mathrm{dm}^{-3}$; $\mathrm{PDS}$ ]: $2.0 \times 10^{-2} \mathrm{~mol} \mathrm{dm}^{-3}$; [CTMAB]: $2.0 \times 10^{-2}$ mol dm${ }^{-3} ;\left[\mathrm{H}^{+}\right]$: $0.50 \mathrm{~mol} \mathrm{dm}{ }^{-3} ;[\mu]: 0.20 \mathrm{~mol} \mathrm{dm}{ }^{-3}$; time: $60 \mathrm{~min}$; temperature: $60 \pm 1{ }^{\circ} \mathrm{C}$; ultrasound condition: $25 \mathrm{kHz} / 300 \mathrm{~W}$ in the polarity of the solvents, which facilitates greater transfer of peroxydisulfate ion from aqueous phase to organic phase $[64,65]$.

\section{Mechanism of phase-transfer catalyzed radical polymerization of acrylonitrile}

Scheme 3 represents the reactions characterizing the polymerization of acrylonitrile (M) initiated by $\mathrm{K}_{2} \mathrm{~S}_{2} \mathrm{O}_{8}$ / PTC in ethyl acetate/water two-phase systems. The dissociation of $\mathrm{QX}, \mathrm{K}_{2} \mathrm{~S}_{2} \mathrm{O}_{8}$ and formation of $\mathrm{QS}_{2} \mathrm{O}_{8}$ was take place in aqueous phase. Subsequently, initiation of polymerization ocuurs in organic phase. These process was depicted in Eqs. (1)-(5). Applying general principles of free radical polymerization and steady-state hypothesis to radical species, the rate law for this mechanism can be derived [35, 65] as follows:

$R_{\mathrm{p}}=k_{\mathrm{p}}\left[\frac{k_{\mathrm{d}} K_{3} f}{k_{t}}\right]^{1 / 2}\left[\mathrm{Q}^{+}\right]_{\mathrm{W}}^{1}\left[\mathrm{~S}_{2} \mathrm{O}_{8}^{2-}\right]_{\mathrm{W}}^{1}[\mathrm{M}]^{1}$.

The above equation satisfactorily explains all the experimental observations for phase-transfer catalyzed radical polymerization of acrylonitrile under ultrasound and silent condition.

\section{Analysis of poly (acrylonitrile)}

\section{Determination of viscosity average molecular weight of poly (acrylonitrile)}

The viscosity average molecular weight $\left(M_{\mathrm{v}}\right)$ of the poly (acrylonitrile) was determined using the intrinsic and reduced viscosity of the polymer solution obtained from viscosity measurement. Viscosity measurements were performed in an Ubbelohde viscometer. The principle behind capillary viscometry is the Poiseuille's law, which states that the time of flow of a polymer solution through a thin capillary is proportional to the viscosity of the solution. The flow time of the pure solvent and different concentration of the polymer solution was measured (Fig. 8). The few important and well-established terms related to viscosity of polymer solutions are defined as follows: relative viscosity, $\eta_{\mathrm{r}}=\eta / \eta_{\mathrm{o}}$ (flow time of polymer solution/ flow time of pure solvent); specific viscosity, $\eta_{\mathrm{sp}}=\eta_{\mathrm{r}}-1$; 
Scheme 3 Ultrasound and radical polymerization process of AN-PTC-PDS in two-phase system

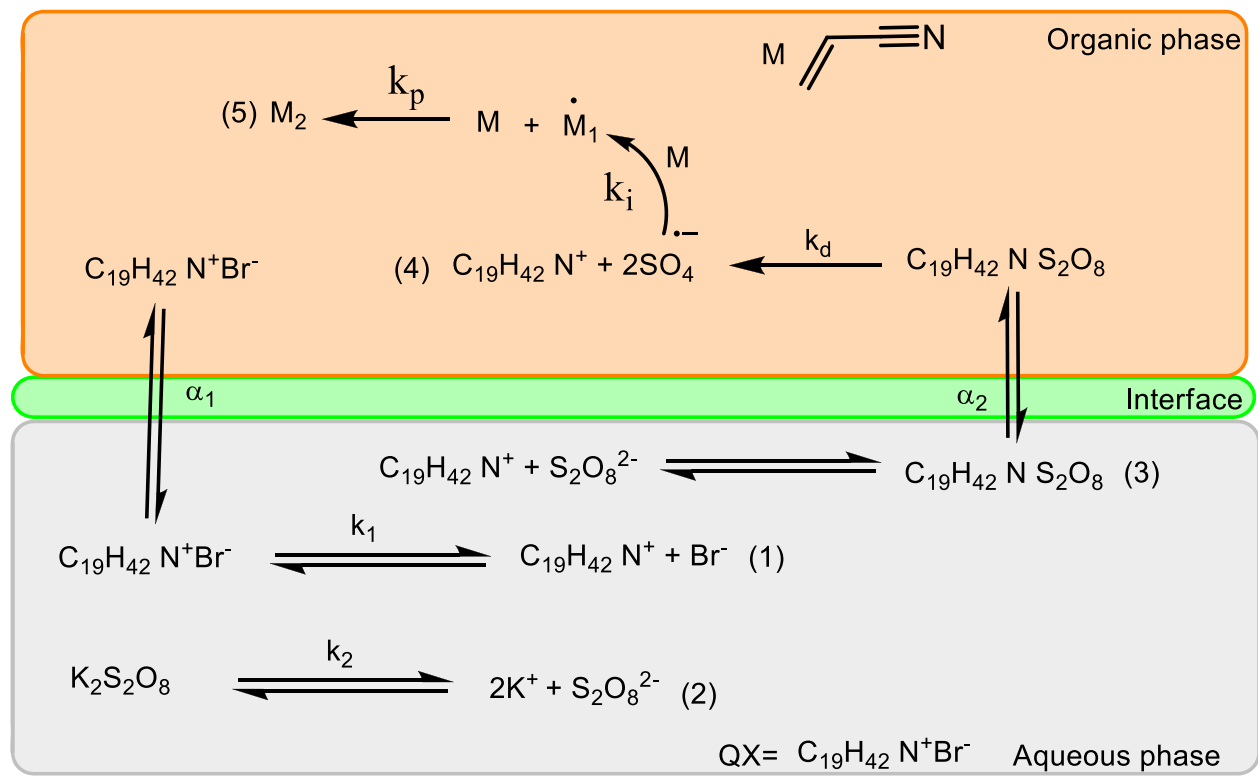

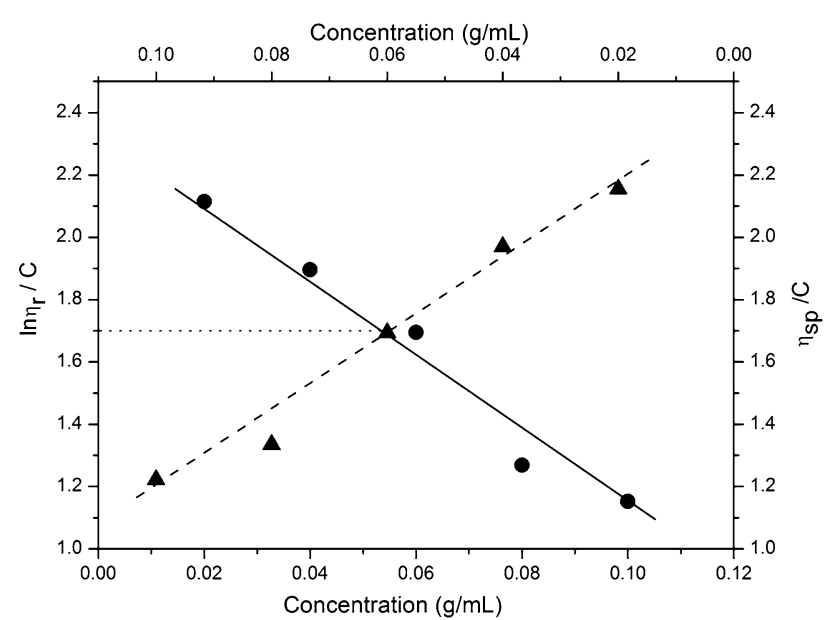

Fig. 8 Determination of viscosity average molecular weight $\left(M_{\mathrm{v}}\right)$ of poly(acrylonitrile)

reduced viscosity, $\eta_{\mathrm{red}}=\eta_{\mathrm{sp}} / C$; That the intrinsic viscosity of the polymer is related to its molecular weight was related by Mark-Houwink equation. $[\eta]=K M_{\mathrm{v}}^{a}$, where ' $K$ ' and ' $a$ ' are constants for a polymer, solvent at a temperature $\left(K=3.93 \times 10^{-4} ; \quad a=0.750\right.$ for $\mathrm{DMF}$ at $\left.30 \pm 1{ }^{\circ} \mathrm{C}\right), M_{\mathrm{v}}$ represents the viscosity average molecular weight of the polymer. The viscosity average molecular weight of the PAN was found $6.8526 \times 10^{4} \mathrm{~g} \mathrm{~mol}^{-1}$.

\section{FT-IR analysis of poly (acrylonitrile)}

The FT-IR spectrum of poly (acrylonitrile) was presented in the Fig. 9. Pellets of about $50 \mathrm{mg}$ of $\mathrm{KBr}$ powder containing finely grained powder of polymer sample were made before recording. The FT-IR spectroscopy confirmed

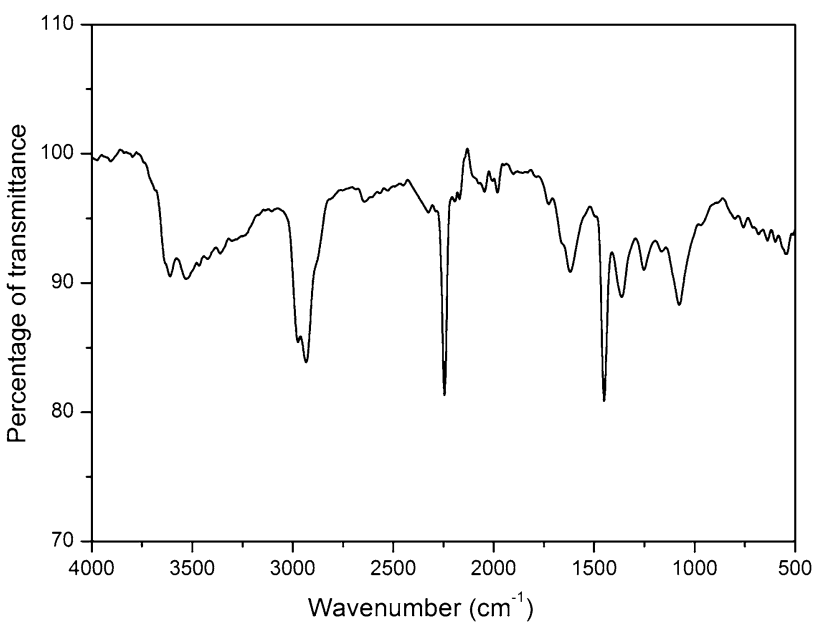

Fig. 9 FT-IR spectra of poly (acrylonitrile)

that the distinct absorption band of $2240 \mathrm{~cm}^{-1}$ corresponds to nitrile $(-\mathrm{CN})$ group of polymer. The other discrete bands of 2922,1452 and $1366 \mathrm{~cm}^{-1}$ were assigned to $-\mathrm{CH}$ stretching of $-\mathrm{CH}_{2}$ group, $-\mathrm{CH}$ deformation stretching of $\mathrm{CH}_{2}$ group and $-\mathrm{CH}$ stretching of $-\mathrm{CH}$ group, respectively, of the polymer.

\section{TGA of poly (acrylonitrile)}

The thermal curve of the poly (acrylonitrile) can be explained with few succinct steps. The shape of the TG curve recorded in an inert atmosphere (Fig. 10) resembles those reported elsewhere $[67,68]$. The heating of the PAN induces chemical reactions, such as cyclization, degradation and thermal cross-linking and the mechanisms of these processes depend on the heating rate, medium, the mass of 


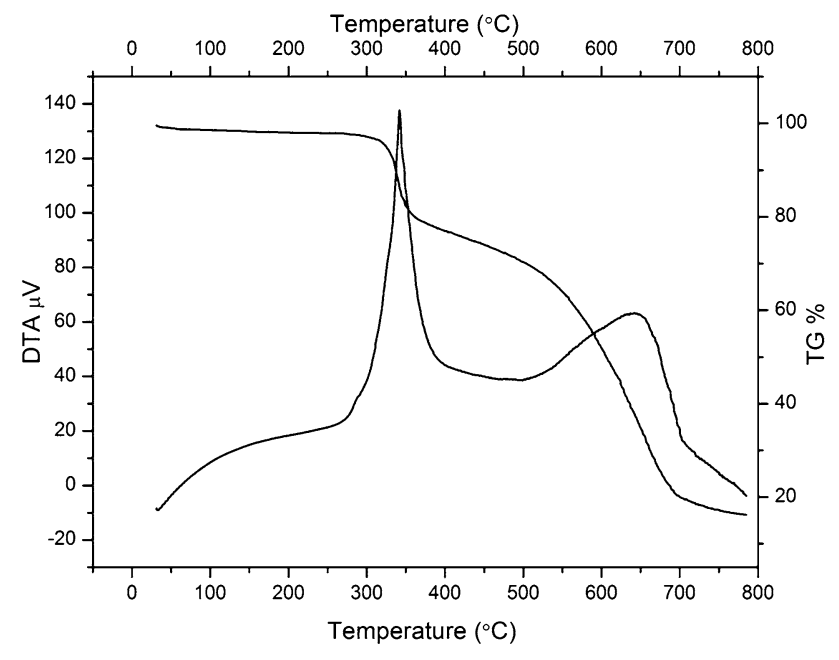

Fig. 10 TG-DTA analysis of poly (acrylonitrile)

the polymer and the other type of materials present in polymer. TGA curve demonstrates that the weight loss caused by the pyrolytic reactions mainly occurred at around $300{ }^{\circ} \mathrm{C}$ for pure PAN. The cyclization reactions continue until the residual nitrile groups do not react with other functional groups. The thermogram showed three mass loss steps, yielding a residual mass of ca. $18 \%$. The first mass loss begins around $300{ }^{\circ} \mathrm{C}$ and is associated with nitrile oligomerization, which produces volatile products $\left(\mathrm{NH}_{3}, \mathrm{HCN}, \mathrm{CH}_{3} \mathrm{CN}\right.$ etc.). The second stage of the PAN degradation occurs at $354-492{ }^{\circ} \mathrm{C}$ with weight loss of $19 \%$ and it is related to the thermal degradation reaction of the polymer, induced by thermal factor [69]. In the third stage, between the temperatures of $492-691{ }^{\circ} \mathrm{C}$ a steady weight decrease was observed with total weight loss of $63 \%$, indicating complete evaporation of polymeric chain fragments from polymer.

\section{Conclusions}

We have successfully accomplished the effective radical polymerization of acrylonitrile in two-phase system with the help of PTC and ultrasound combined techniques. Results revealed that the ultrasound boosted the rate of polymerization significantly compare to silent condition. The $R_{p}$ was significantly enhanced by variation of various experimental parameter under ultrasonic compare to silent condition. Ultrasound condition could be the cause for the fast dissociation of initiator hence more free radicals produced and also enhances the mixing of two phase effectively. The AN-PTC-PDS system was followed order of unity with respect to monomer, initiator and catalyst. The energy of activation $\left(E_{\mathrm{a}}\right)$ and other thermodynamic parameters were calculated for both conditions. Based on obtained kinetic results, a simple kinetic model was developed and plausible mechanism was proposed. The prepared polymer was confirmed by FT-IR spectroscopy and thermally stable up to $300{ }^{\circ} \mathrm{C}$. It is hoped that this investigation may helps towards the use of combined approach of PTC and ultrasound in polymerization of different/novel functional monomers. There are several factors to consider in polymerization reaction although the combination of PTC and ultrasound is one of the techniques to obtain high yield in polymerization.

Acknowledgements The work was carried out under financial support of Science and Engineering Research Board (DST-SERB), New Delhi, India, through the start-up research Grant no. SB/FT/CS-008/ 2014. Authors also thank the Management of B S Abdur Rahman Crescent University for the encouragement.

\section{Compliance with ethical standards}

Conflict of interest The authors declare that there is no conflict of interest regarding the publication of this article.

Open Access This article is distributed under the terms of the Creative Commons Attribution 4.0 International License (http:// creativecommons.org/licenses/by/4.0/), which permits unrestricted use, distribution, and reproduction in any medium, provided you give appropriate credit to the original author(s) and the source, provide a link to the Creative Commons license, and indicate if changes were made.

\section{References}

1. Cunningham MF, Hutchinson RA (2003) Industrial applications and processes. Handbook of radical polymerization. Wiley, Hoboken, pp 333-359

2. Matyjaszewski K, Davis Thomas P (2003) Handbook of radical polymerization. Wiley, Hoboken

3. Braun D (2009) Origins and development of initiation of free radical polymerization processes. Int J Polym Sci 2009:10

4. Ishige T, Hamielec AE (1973) Solution polymerization of acrylamide to high conversion. J Appl Polym Sci 17:1479-1506

5. Takahashi T, Hori Y, Sato I (1968) Coordinated radical polymerization and redox polymerization of acrylamide by cericammoniumnitrate. J Polym Sci Part A Polym Chem 6:2091-2102

6. Tunca U, Serhatli IE, Yagci Y (1989) Polymerization of acrylamide initiated by the redox system Ce(IV)-4,4'-azobis (4-cyano pentanol). Polym Bull 22:483-488

7. Cakmak I, Hazer B, Yagci Y (1991) Polymerization of acrylamide by the redox system cerium (IV) with poly (ethylene glycol) with azo groups. Eur Polym J 27:101-103

8. Erim M, Erciyes AT, Serhatli IE, Yagci Y (1991) Aqueous polymerization of acrylamide initiated by $4,4^{\prime}$-azobis (4-cyano pentanol) and chain extension of polyacrylamide by means of ceric ion redox systems. Polym Bull 27:361-366

9. Oster GK, Oster G, Parti G (1957) Dye-sensitized photo polymerization of acrylamide. J Am Chem Soc 79:595-598

10. Ogumij Z, Tari I, Takahara Z, Yoshizawa S (1974) The electroinitiated polymerization of acrylamide in an aqueous solution of trifluoroacetic acid and potassium trifluoroacetate. Bull Chem Soc Jpn 47:1843-1846 
11. Chapiro A, Perec L (1971) Polymerization of acrylamide using radiochemical technique in different nature. Eur Polym $\mathbf{J}$ 7:1335-1355

12. Jones RA (2001) Quaternary ammonium salts: their use in phase transfer catalysis. Academic Press, New York

13. Starks CM, Liotta C (1994) Phase transfer catalysis: principles and techniques. Academic Press, New York

14. Dehmlow EV, Dehmlow SS (1983) Phase transfer catalysis, monographs in modern chemistry, vol 11. Verlag Chemie, Weinheim

15. Weber WP, Gokel GW (1977) Phase transfer catalysis in organic synthesis. Springer, Berlin

16. Sasson Y, Neumann R (1997) Handbook of phase transfer catalysis. Chapman and Hall, New York

17. Starks CM, Liotta CL, Halpern M (1994) Phase transfer catalysis: fundamentals, applications and industrial perspectives. Chapman and Hall, New York

18. Makosza M, Fedorynski M (2003) Phase transfer catalysis. Catal Rev 45:321-367

19. Albanese D (2003) Liquid-liquid phase transfer catalysis: basic principles and synthetic applications. Catal Rev 45:369-395

20. Jwo J-J (2003) Phase transfer catalysis: fundamentals and selected systems. Catal Rev 45:397-461

21. Yang H-M, Wu H-S (2003) Interfacial mechanism and kinetics of phase transfer catalysis. Catal Rev 45:463-540

22. Balakrishnan T, Damodarkumar S (2000) Phase transfer catalysis: free radical polymerization of acrylonitrile using peroxymonosulphate/tetrabutylphosphonium chloride catalyst system: a kinetic study. J Appl Polym Sci 76:1564-1571

23. Balakrishnan T, Damodarkumar S (2000) Phase transfer catalysed free radical polymerization: kinetics of polymerization of butyl methacrylate using peroxymonosulphate/tetrabutyl phosphonium chloride catalyst system. Ind $\mathrm{J}$ Chem $\mathrm{Sec} A$ 39A:751-755

24. Jayakrishnan A, Shah DO (1983) Phase-transfer-catalysed freeradical polymerization: kinetics of polymerization of methyl methacrylate using ammonium peroxydisulfate/hexadecyl pyridinium chloride in ethyl acetate/water. J Polym Sci Polym Chem Edn 21:3201-3208

25. Umapathy MJ, Mohan D (1999) Studies on phase transfer catalysed polymerization of acrylonitrile. Hung J Ind Chem 27(4):245-250

26. Umapathy MJ, Balakrishnan T (1998) Kinetics and mechanism of polymerization of methyl methacrylate initiated by phase transfer catalyst-ammonium perdisulfate system. J Polym Mater $15: 275-278$

27. Umapathy MJ, Mohan D (1999) Studies on phase transfer catalyzed polymerization of glycidyl methacrylate. J Polym Mater 16(2):167-171

28. Umapathy MJ, Mohan D (2001) Phase transfer polymerization of butyl methacrylate using potassium peroxydisulfate as initiatora kinetic study. Indian J Chem Tech 8(6):510-514

29. Umapathy MJ, Malaisamy R, Mohan D (2000) Kinetics and mechanism of phase transfer catalyzed free radical polymerization of methyl acrylate. J Macromol Sci Part A Pure Appl Chem 37(11):1437-1445

30. Thajudeen H, Jamal Ahamed VS, Shabeer TK (2008) Phase transfer catalysis: polymerization kinetics and mechanism of methyl acrylate. Int J Polym Mater 57:904-917

31. Damodarkumar S, Perumal A (2007) Kinetics of free radical polymerization of methylacrylate initiated by potassium peroxomonosulphate and tetrabutyl phosphonium chloride. Asian J Chem 19:5081-5088

32. Jamal Ahamed VS, Thajudeen H, Shabeer TK (2012) Radical polymerization of methyl methacrylate (MMA) initiated by $\mathrm{KHSO}_{5}-\mathrm{BTBAC}$ system-a kinetic study. J Polym Res 19:9779
33. Murugesan V, Umapathy MJ (2016) Phase transfer catalyst aided radical polymerization of $n$-butyl acrylate in two phase system-a kinetic study. Int J Ind Chem 7:441-448

34. Vajjiravel M, Umapathy MJ, Bharathbabu M (2007) Polymerization of acrylonitrile using potassium peroxydisulfate as an initiator in the presence of a multisite phase-transfer catalyst: a kinetic study. J Appl Polym Sci 105:3634-3639

35. Vajjiravel M, Umapathy MJ (2008) Synthesis and characterization of multi-site phase transfer catalyst: application in radical polymerisation of acrylonitrile-a kinetic study. J Polym Res 15:27-36

36. Vajjiravel M, Umapathy MJ (2008) Multi-site phase transfer catalyst assisted radical polymerisation of glycidyl methacrylate using potassium peroxydisulphate as initiator-a kinetic study. J Polym Res 15:235-240

37. Vajjiravel M, Umapathy MJ (2008) Free radical polymerisation of methyl methacrylate initiated by multi-site phase transfer catalyst-a kinetic study. Colloid Polym Sci 286:729-738

38. Vajjiravel M, Umapathy MJ (2009) Kinetics and mechanism of multi-site phase transfer catalyzed radical polymerization of ethyl methacrylate. Int J Polym Mater 58:61-76

39. Vajjiravel M, Umapathy MJ (2010) Multi-site phase transfer catalyzed radical polymerization of $n$-butyl methacrylate: a kinetic study. Chem Eng Commun 197:352-365

40. Vajjiravel M, Umapathy MJ (2010) Synthesis, characterization and application of a multi-site phase transfer catalyst in radical polymerization of $n$-butyl methacrylate-a kinetic study. Int $\mathrm{J}$ Polym Mater 59:647-662

41. Vajjiravel M, Umapathy MJ (2011) Kinetics of radical polymerization of glycidyl methacrylate initiated by multi-site phase transfer catalyst-potassium peroxydisulfate in two-phase system. J Appl Polym Sci 120:1794-1799

42. Usha J, Shymalavathy P, Umapathy MJ (2009) Free radical polymerization of acrylonitrile using potassium peroxydisulfate initiator and a phase transfer catalyst. Int $\mathrm{J}$ Polym Mater 58:99-110

43. Mathur R, Mathur S, Kanoongo N, Narang CK, Mathur NK (1992) Use of phase transfer catalysts to aid initiation in suspension vinyl polymerization. Polymer 33:217-218

44. Osaitis A, Makuška R (1994) Homolytic scission of peroxydisulfate under conditions of free-radical phase-transfer-catalyzed polymerization. Polymer 35:4896-4900

45. Chen D, Sharma SK, Mudhoo A (2012) Hand book on applications of ultrasound: sonochemistry for sustainability. CRC Press, London

46. Ashokkumar M (2016) Handbook of ultrasonics and sonochemistry. Springer, Singapore

47. Bang JH, Suslick KS (2010) Applications of ultrasound to the synthesis of nanostructured materials. Adv Mater 22:1039-1059

48. Paulusse Jos MJ, Sijbesma RP (2006) Ultrasound in polymer chemistry: revival of established technique. J Polym Sci Part A Polym Chem 44:5445-5453

49. Bhanvase BA, Sonawane SH (2014) Ultrasound assisted in situ emulsion polymerization for polymer nanocomposite: a review. Chem Eng Process 85:86-107

50. Adewuyi YG (2001) Sonochemistry: environmental science and engineering applications. Ind Eng Chem Res 40:4681-4715

51. Mason TJ (1997) Ultrasound in synthetic organic chemistry. Chem Soc Rev 26:443-451

52. Wang ML, Rajendran V (2007) Kinetics for dichlorocyclopropanation of 1,7-octadiene under the influence of ultrasound assisted phase-transfer catalysis conditions. J Mol Catal A Chem 273:5-13

53. Wang ML, Rajendran V (2006) A kinetic study of thioether synthesis under influence of ultrasound assisted phase-transfer catalysis conditions. J Mol Catal A Chem 244:237-243 
54. Wang ML, Rajendran V (2007) Ultrasound assisted phasetransfer catalytic epoxidation of 1,7-octadiene-a kinetic study. Ultrason Sonochem 14:46-54

55. Wang ML, Rajendran V (2007) Ethoxylation of p-chloronitrobenzene using phase-transfer catalysts by ultrasound irradiation-a kinetic study. Ultrason Sonochem 14:368-374

56. Wang ML, Chen WH (2009) Kinetic study of synthesizing dimethoxydiphenylmethane under phase-transfer catalysis and ultrasonic irradiation. Ind Eng Chem Res 48:1376-1383

57. Korkut I, Bayramoglu M (2014) Various aspects of ultrasound assisted emulsion polymerization process. Ultrason Sonochem 21:1592-1599

58. Degirmenci M, Catalgil-Giz H, Yagci Y (2004) Synthesis of block copolymers by combined ultrasonic irradiation and reverse atom transfer radical polymerization processes. J Polym Sci Polym Chem 42:534-540

59. Cass P, Knower W, Pereeia E, Holmes NP, Hughes T (2010) Preparation of hydrogels via ultrasonic polymerization. Ultrason Sonochem 17:326-332

60. Sankar K, Rajendran V (2012) Ultrasound assisted free radical polymerization of glycidyl methacrylate by a new di-site phasetransfer catalyst system: a kinetic study. Ultrason Sonochem 19:1205-1212

61. Sankar K, Rajendran V (2013) Polymerization of ethyl methacrylate under the influence of ultrasound assisted a new multi-site phase-transfer catalyst system - a kinetic study. Ultrason Sonochem 20:329-337
62. Loganathan S, Rajendran V (2013) Ultrasound assisted polymerization of $N$-vinyl imidazole under phase-transfer catalysis condition-a kinetic study. Ultrason Sonochem 20:308-313

63. Murugan E, Thamizarasu G (2012) Synthesis and characterization of new soluble multi-site phase transfer catalysts and their catalysis in free radical polymerization of methyl methacrylate aided by ultrasound-a kinetic study. J Appl Polym Sci 125:263-273

64. Vivekanand PA, Wang ML, Hsieh YM (2013) Sonolytic and silent polymerization of methacrlyic acid butyl ester catalyzed by a new onium salt with bis-active sites in a biphasic system-a comparative investigation. Molecules 18:2419-2437

65. Marimuthu E, Murugesan V (2017) Influence of ultrasonic condition on phase transfer catalyzed polymerization of methyl methacrylate in two phase system-a kinetic study. Ultrason Sonochem 38:560-569

66. Brandrup J, Immerugut EH, Grulke EA (1999) Polymer handbook, 4th edn. Wiley, New York

67. Grassie N, Scott G (1988) Polymer degradation and stabilization. Cambridge University Press, New York, p 222

68. Korobeinyk AV, Raymond LD, Sergey Whitby, Mikhalovsky V (2012) High temperature oxidative resistance of polyacrylonitrile-methylmethacrylate copolymer powder converting to a carbonized monolith. Eur Polym J 48:97-104

69. Van Krevelen DW, Nijenhuis KT (2009) Chemical degradation. Properties of polymers, 4th edn. Elsevier, Amsterdam, pp 779-786 